\title{
0 infame solitário: o que o documentário Solitário Anônimo pode acrescentar aos debates sobre educação em saúde?
}

Ana Claudia Coelho de Oliveira*, Vera Helena Ferraz de Siqueira**

\section{Resumo}

Este artigo propõe reflexões sobre educação em saúde, particularmente no que diz respeito à formação ético-política dos profissionais da área, à luz das ideias de Michel Foucault. Toma o vídeo Solitário Anônimo, produzido em 2007 pela antropóloga e docente Debora Diniz, como desencadeador dessas reflexões, particularmente no que tange à incidência do poder sobre a vida retratada na tensa relação entre paciente idoso e agentes de cuidado na cena hospitalar. Busca articular o pensamento foucaultiano com as noções de normal/patológico, saúde/doença, risco em saúde e qualidade de vida, substratos de práticas e teorias no campo da educação em saúde.

\section{Palavras-chave}

saúde e educação; profissional da saúde; Michel Foucault; expressão audiovisual; velhice.

* Secretaria de Estado de Saúde do Rio de Janeiro, Gerência de Saúde Mental. Núcleo de Tecnologia Educacional para a Saúde (Nutes) da Universidade Federal do Rio de Janeiro (UFRJ), Brasil. anaclauco@hotmail.com.

** Professora do Nutes/ UFRJ, Rio de Janeiro, Brasil. verahfs@yahoo.com.br. 


\title{
The lonely infamous: how can the documentary entitled "Alone and Anonymous" contribute to debates on health education?
}

\begin{abstract}
This article presents reflections on health education, mainly related to the ethical and political formation of health professionals, inspired on Michel Foucault's ideas. It takes the documentary 'Alone and Anonymous', produced in 2007 by the anthropologist and professor Debora Diniz, as a trigger for such reflections, more particularly as it relates to the incidence of power over life represented on the tense relationship between an old patient and health care providers in a hospital scenario. It attempts to articulate Foucault's concepts with the notions of normal/pathological, health/disease, health risks and quality of life, which underlie practices and theories in the area of health education.
\end{abstract}

Key words health and education; health professional; Foucault, Michel; audiovisual expression; old Age. 
Solitário Anônimo ${ }^{1}$ registra a história de um homem, encontrado em grave estado de desnutrição, sem qualquer referência pessoal ou familiar, internado numa unidade hospitalar pública à sua revelia: intencionava morrer por inanição... No bolso, um bilhete datado de "20/09/006", no qual se lê: "A quem interessar possa. Meu nome: Solitário Anônimo. Não tenho familiares nem parentes nesta região do país”.

De saída, somos lançadas no vazio angustiante da impossibilidade de nomear, explicar, classificar o que se apresenta diante de nós. Atravessadas pela racionalidade moderna, angustiamo-nos diante da falta de respostas apaziguadoras: quem será aquele homem? O que o teria levado a desprender-se de tal modo de seus vínculos familiares e sociais? Por que não revela seu nome, ainda que fictício fosse, e insiste em nomear-se Solitário Anônimo?

Sua inquietante atitude nos leva a pensar em nosso próprio modo de estar no mundo: "somos Fulanas ou Beltranos de tal, filhas(os) de Cicrana e Cicrano, nível superior, formadas(os) pela universidade tal, na carreira qual, há tantos anos..." e por aí vai. Nossa história parece nos conferir espessura e, assim, existimos. Mas, a despeito da severa desnutrição e de sua recusa em assumir-se simbolicamente, nosso personagem também existe. E sua existência se materializa justamente por sua desconcertante insistência em não existir: o paciente tentava se matar... Ou seria mais exato dizer que sua atitude consistia na recusa a viver de um certo modo?

Movidas - mais que isso, instigadas - pela tensão que molda a relação entre personagem e agentes de cuidado na cena hospitalar, pretendemos modular nossas reflexões sobre educação em saúde, recorrendo ao pensamento de Michel Foucault, filósofo que se destaca pela agudeza e pela atualidade de suas análises acerca da complexa trama de saber-poder, vigente na contemporaneidade ocidental, que constitui e sustenta a hegemonia de práticas médicas comprometidas com a manutenção de determinadas regulações a serviço da biopolítica.

Para tanto, vale começar refletindo sobre a incidência do poder, manifestado na época clássica pelo direito de matar, transmutando-se modernamente no direito de fazer viver, para, em seguida, destacar o exercício do poder em suas faces individual e coletiva - as “disciplinas do corpo" e as "regulações da população”. Na sequência, consideramos relevante trazer à discussão as noções de normal e patológico em seu inevitável entrelaçamento com as de saúde e

1. 'Solitário Anônimo': documentário realizado em 2007 por Debora Diniz, antropóloga, docente da Universidade de Brasília/DF, Brasil, e pesquisadora da ONG Anis - Instituto de Bioética, Direitos Humanos e Gênero. Produção disponivel em: 〈http://www.youtube.com/watch?v=Uw6 zvieFwo〉 (parte 1) e 〈http://www.youtube.com/watch? $\mathrm{v}=\mathrm{V}_{0} K_{53}$ 4AXvl> (parte 2). Acesso em: 4 out. 2011. 
doença, uma vez que toda produção - teórica e prática - pertencente ao campo da educação em saúde funda-se, em última instância, em tais concepções. Por fim, pretendemos articular o que foi levantado com as noções de qualidade de vida e risco em saúde a fim de suscitar questionamentos sobre os parâmetros de bem viver construídos por nossa sociedade e amargem de manobra de que dispomos em meio a tais regulações - “o cuidado de si”, para Foucault.

Antes de levar à frente o proposto, vale um pequeno, porém importante, preâmbulo: a despeito da sistematização de sua obra em três grandes fases - arqueológica, genealógica e ética - atribuindo-se à segunda o ápice da discussão sobre as relações de força que configuram as sociedades ocidentais, pode-se dizer que a questão do poder está no cerne das problematizações de Michel Foucault desde sempre. Porém, mais do que dar visibilidade a condições históricas que forjam determinadas configurações de poder, Foucault, particularmente na última fase de sua obra, assinala que não estamos inelutavelmente enredados nas tramas de um poder substantivo, encarnado em instituições, sujeitadosa relações de força assimetricamente perversas produzidas pelo modus operandi capitalista. Roberto Machado, na introdução escrita para Microfísica do poder, coletânea de reflexões de Michel Foucault (Foucault, 2008, p. xiv) sobre o poder na modernidade, esclarece:

o interessante da análise [de Foucault] é justamente que os poderes não estão localizados em nenhum ponto específico da estrutura social. Funcionam como uma rede de dispositivos ou mecanismos a que nada ou ninguém escapa, a que não existe exterior possível, limites ou fronteiras. Daí a importante e polêmica idéia de que o poder não é algo que se detém como uma coisa, como uma propriedade, que se possui ou não. Não existem de um lado os que têm o poder e de outro aqueles que se encontram dele alijados. Rigorosamente falando, o poder não existe; existem práticas ou relações de poder. (Foucault, 2008, p. xiv).

Ajustando o foco, Castro (2009, p.324) adverte que "o tema do poder é, em realidade, para Foucault, um modo de enfrentar o tema do sujeito". Assim, corroborando o dito, temos as palavras do próprio pensador: "não é o poder, mas o sujeito, que constitui o tema geral de minha pesquisa” (Dreyfus; Rabinow, 1995, p. 232). Pensamos que esse ajuste no foco é de relevância capital por centrar a discussão naquilo 
que de fato importa: a potência transformadora do humano, inspiração para ações inventivas nos campos da educação, da saúde, e da educação em saúde, recorte que particularmente nos interessa.

Diante disso, entendendo que reflexões sobre os instrumentos pedagógicos que utilizamos são necessárias ao enriquecimento de nossas práticas educativas, ao escolher uma peça audiovisual como disparadora de nossa discussão, destacamos o valor desses recursos audiovisuais nos espaços de construção de conhecimento. Endossando a importância desses materiais, Sá e Siqueira (2009, p.1) lembram-nos que

[...] a presença desses suportes em ambientes educacionais pode ser entendida como o reconhecimento do valor da imagem em movimento em ou para ações pedagógicas, o que justifica a crescente importância de estudos que se voltem à compreensão de aspectos relacionados a essa temática.

Ainda em favor da relevância de tais recursos, apresentamos a bela síntese proposta por Duarte a respeito do potencial transformador da imagem em movimento:

[...] seja qual for a pedagogia, o cinema segue ensinando coisas sobre a vida e a morte, coisas sobre o mundo natural e o mundo social e muitas, mas muitas coisas mesmo sobre a humanidade, sua história, suas ruínas, suas culturas, seus afetos e contradições e sobre os mistérios imperscrutáveis da alma humana [...]. (Duarte, 2008, p.3).

Acreditamos que, mesmo não havendo explícita intenção pedagógica, o vídeo que elegemos ensina exemplarmente "coisas sobre a vida e a morte", o que o coloca à frente de tantos materiais elaborados para fins especificamente educativos, mas reduzidos tão somente aos aspectos instrumentais da relação pedagógica. Há que ousar mergulhos nos "mistérios imperscrutáveis da alma humana”, se quisermos produzir saberes que recuperem a integralidade do olhar sobre os indivíduos, homens e mulheres, humanos, acima de tudo. E cremos não restar dúvidas quanto à força da imagem em movimento na dinamização de tais processos.

Solitário Anônimo apresenta um paciente sendo admitido em local que se supõe a emergência de uma unidade pública hospitalar, o que vem a ser confirmado posteriormente. 
Submetido a procedimentos realizados pela equipe de enfermagem, o paciente resiste: dado o seu estado de desnutrição, era necessária a introdução de uma sonda nasogástrica para aporte alimentar balanceado, ato repudiado pelo paciente e qualificado como "selvageria”. Diante da dificuldade em concluir o procedimento - o paciente resiste, tenaz, à intervenção -, a equipe tenta estabelecer algum diálogo que possa levá-lo a cooperar: “como é que é o nome do senhor?” Tratava-se de um velho.

o imperativo do cuidado impõe-se à vontade do indivíduo, e o paciente é vencido. Contudo, ainda lhe restava ao menos uma forma de resistência: não havia como obrigá-lo a se identificar, e o paciente passava seus dias de melhora progressiva incógnito, até mesmo para a autora, com quem, percebe-se, foi estabelecendo, pouco a pouco, relação de confiança. Vemos aí, em movimento, imagens que revelam os fios que tecem a trama de forças que se estabelece entre pacientes e agentes de cuidado, tema que consideramos absolutamente fundamental às reflexões sobre educação em saúde. Reflitamos, pois, acompanhadas(os) por Foucault, começando pelo sugestivo texto “Direito de morte, poder sobre a vida”, último capítulo do livro História da sexualidade 1 - a vontade de saber, que nos parece bastante oportuno para iniciar a discussão, uma vez que nosso personagem lutava pelo direito de dispor de sua própria vida.

Pontua Foucault (2006a, p.147): “um dos privilégios característicos do poder soberano fora o direito de vida e morte", direito inspirado no poder exercido pelos pais de família romanos que dispunham, por exemplo, da vida de seus filhos pelo simples fato de a terem "concedido". Contudo, a relação entre aquele e seus súditos não era levada a tais extremos: para que o soberano dispusesse de suas vidas, eram necessárias duas condições - ameaça direta ou indireta à sua sobrevivência. No primeiro caso, o soberano teria o legítimo direito de tirar a vida daquele que se insurgisse contra ele e, no segundo, de expor seus súditos ao risco de perder a vida em batalhas que visassem à sua proteção e, consequentemente, à manutenção de sua posição de soberania. Assim, nas palavras do pensador:

[...] o soberano só exerce, no caso, o seu direito sobre a vida, exercendo seu direito de matar ou contendo-o; só marca seu poder sobre a vida pela morte que tem condições de exigir. 0 direito que é formulado como "de vida e morte" é, de fato, o direito de causar a morte ou deixar viver (Foucault, 2006a, p.148, grifos do autor). 
Em Solitário Anônimo vemos, justamente, a inversão dessa sentença: a instituição médica, encarnada nos profissionais de saúde que assistem o protagonista na dita sala de emergência, vê-se no direito de causar a vida e não deixar morrer. Como compreender esse deslocamento, que aponta noutra direção?

Como foi dito, antes do período clássico, o direito a que o soberano se atribuía de apreender coisas, tempo, corpos e, por fim, a vida, apoderando-se dela, inclusive para suprimi-la (Foucault, 2006a), era a expressão de poder característica desse momento histórico. No entanto, na época clássica, transformações profundas nessas formas de exercício de poder puderam ser observadas: “o poder [é, agora,] destinado a produzir forças, a fazê-las crescer, e a ordená-las mais do que a barrá-las, dobrá-las ou destruí-las." Foucault (2006a, p.148). Ainda com o filósofo, aprendemos que

o princípio: poder matar para poder viver, que sustentava a tática dos combates, tornou-se princípio de estratégia entre Estados; mas a existência em questão já não é aquela - jurídica - da soberania, é outra - biológica - de uma população. (Foucault, 2006a, p.149).

Na medida em que o foco recai sobre a vida da população, ampliam-se e sofisticam-se os mecanismos disciplinares: é preciso estender o poder a tudo e a todos, sendo "a morte o limite, o momento que the escapa [...] o ponto mais secreto da existência, o mais “privado” (Foucault, 2006a, p.151, grifo do autor). Nesse ponto, tendo em vista que o personagem central do documentário tentava se matar, torna-se interessante acompanhar, na íntegra, as observações do pensador acerca do suicídio:

não deve surpreender que o suicídio - outrora crime, pois era um modo de usurpar o direito de morte que somente os soberanos, o daqui debaixo ou do além, tinham o direito de exercer - tenha se tornado, no decorrer do século XIX, uma das primeiras condutas que entraram no campo da análise sociológica; ela fazia aparecer, nas fronteiras e nos interstícios do poder exercido sobre a vida, o direito individual e privado de morrer. Essa obstinação em morrer, tão estranha e, contudo, tão regular, tão constante em suas manifestações, [...] foi uma das primeiras surpresas de uma sociedade em que o poder político acabava de assumir a tarefa de gerir a vida. (Foucault 2006a, p.151). 
Mas, como articular tais reflexões às questões de educação em saúde que queremos debater? Vale, antes, um passeio histórico sobre quando e como tal poder sobre a vida começou a ser engendrado.

\section{Entre disciplinas e regulações...}

Segundo Foucault (2006a, p.151), “o poder sobre a vida desenvolveu-se a partir do século XVII" e se fundamentou em dois polos não antagônicos, ao contrário, inter-relacionados: as "disciplinas do corpo" e as "regulações da população" ou, dito de outro modo, a "anátomo-política do corpo" e a "biopolítica da população".

De acordo com o filósofo, o primeiro polo a se constituir concebia "o corpo como máquina”: era necessário extrair o máximo de utilidade dos corpos com vistas ao seu aproveitamento econômico e, para tal, se faziam imprescindíveis formas de controle, "procedimentos de poder" - as "disciplinas" - que configuravam a dita "anátomo-política do corpo humano". O segundo polo, desenvolvido a partir da metade do século XVIII, concentrou-se no "corpo-espécie", ou seja, no corpo como "suporte dos processos biológicos", entendidos como os nascimentos, as mortes, o nível de saúde, a longevidade, controlados por mecanismos reguladores, a chamada "biopolítica". Acompanhemos a síntese proposta pelo autor:

[...] a instalação, durante a época clássica desta grande tecnologia de duas faces - anatômica e biológica, individualizante e especificante, voltada para os desempenhos do corpo e encarando os processos da vida - caracteriza um poder cuja função mais elevada já não é mais matar, mas investir sobre a vida, de cima a baixo.

A velha potência da morte em que se simbolizava o poder soberano é agora, cuidadosamente, recoberta pela administração dos corpos e pela gestão calculista da vida. Desenvolvimento rápido, no decorrer da época clássica, das disciplinas diversas - escolas, colégios, casernas, ateliês; aparecimento, também, no terreno das práticas políticas e observações econômicas, dos problemas de natalidade, longevidade, saúde pública, habitação e migração; explosão, portanto, de técnicas diversas e numerosas para obterem a sujeição dos corpos e o controle das populações. Abre-se, assim, a era de um 'biopoder'. (Foucault, 2006a, p.152, grifo do autor). 
De volta ao documentário, acompanhando o desenrolar do vídeo, vemos claramente em ação os mecanismos regulatórios da biopolítica: à medida que o paciente melhorava, fazia-se necessário saber quem era aquele homem, pois a descoberta de eventuais elos de parentesco desobrigaria o Estado de seus cuidados, ao chegar o momento oportuno, ou o autorizaria a internar o paciente numa instituição asilar, caso não houvesse parentes a assumi-lo quando da alta médica.

Entra em cena o Serviço Social, valendo-se de pistas para investigar o passado do paciente, que logo vira matéria jornalística. O semblante "infame”, pertencente a "essas milhares de existências destinadas a passar sem deixar rastro" (Foucault, 2006b, p. 207), destituído de qualquer valoração que the pudesse render alguma deferência, é substituído por outro, carregado de atributos que o elevam ao estatuto de “cidadão" de plenos direitos e deveres: trata-se de um homem formado em Direito e Filosofia pela Universidade de Brasília, poliglota, amante de xadrez, música erudita, possuidor de conhecimentos religiosos. O homem incógnito, mais um número na multidão, destaca-se. Mas, a despeito disso, permanece reafirmando sua condição infame, exercitando o modo de existir para si escolhido: seu nome? Solitário Anônimo.

A esse ponto, poderíamos pensar: 'tal recusa em se identificar e restabelecer seus vínculos familiares e sociais não seria decorrência de alguma patologia psiquiátrica?' A medicina, em sua sanha reguladora, disporia, sem dúvida, de recursos suficientes para esquadrinhar seu comportamento, perscrutando e determinando o que estaria na raiz de suas atitudes. Os tratados de psiquiatria são férteis em classificar condutas, atribuindo-lhes codificações específicas, de acordo com os sinais tomados como patognomônicos. Além disso, trata-se de um paciente velho, condição que alarga as suspeitas de alguma patologia mental, posto que, como adverte Groisman (2002), é preciso considerar a névoa que embaça os limites entre o normal e o patológico na velhice.

$\mathrm{E}$, nesse ponto, estamos diante de um tema que consideramos absolutamente fundamental aos debates sobre educação em saúde: as noções de normal e patológico que, por sua vez, conduzem à discussão sobre o que é considerado saúde e doença em nossa sociedade. Entendemos que tal problematização possa vir a enriquecer o debate sobre a maneira como lidamos com o outro em nossas relações de cuidado profissional (ou, mesmo, para além delas) e, particularmente, sobre o modo como nos relacionamos com os "mais velhos",

2. Em transporte coletivo, ouço, casualmente, diálogo entre dois homens - um jovem e outro idoso - chamando minha atenção o uso da expressão "mais velho", como forma de tratamento, fato que me pareceu bastante interessante por carregar implícita a ideia de que ele mesmo (o mais jovem) também estaria envelhecendo, o que contraria a atitude que prevalece em nossa sociedade de tomar 0 velho como 0 outro: 0 idoso acabara de recuperar-se de um mal-estar e 0 jovem que 0 acudira, adverte - "Ô, mais velho, é preciso andar acompanhado!..." 
em face aos desafios impostos pelo galopante aumento do número de idosos em nosso país.

\section{Normal/patológico, saúde/doença... c'est tout la même chose?}

Assistimos, em nossos tempos, a uma superposição - que parece bastante natural - entre os binômios normal/patológico - saúde/doença, no qual os termos normal e saúde, ocupando o mesmo lugar na equação que os alinha, dão forma à sentença: ser saudável, pois, é ser normal. Contudo, se imaginarmos, do ponto de vista lógico, a frase inversa ser doente é portar alguma patologia, estaremos, em última análise, diante de uma falsa oposição entre as noções de normal e patológico, pois, recombinando os termos, outra conclusão lógica que poderíamos extrair desse raciocínio - se estou saudável, não estou doente/se não estou doente, estou saudável - não pode ser aceita como um fato total e absoluto, uma vez que a noção de saúde vai muito além da mera ausência de doenças ${ }^{3}$. Neste ponto, convoquemos Canguilhem (2009, p.11):

fizemos também questão de apresentar nossas concepções em ligação com o exame crítico de uma tese, geralmente adotada no século XIX, relativa às relações entre o normal e o patológico. Trata-se de uma tese segundo a qual os fenômenos patológicos são idênticos aos fenômenos normais correspondentes, salvo pelas variações quantitativas.

3. A despeito de todas as críticas e questionamentos que a definição de saúde apresentada por Canguilhem (2005, p.43), de autoria da Organização Mundial de Saúde, possa ter suscitado, vale incluir a citação do autor: "a ampliação histórica do espaço no qual se exerce o controle administrativo da saúde dos indivíduos desembocou, nos dias de hoje, em uma Organização Mundial da Saúde, que não podia delimitar seu domínio de intervenção sem que ela mesma publicasse sua própria definição de saúde. Ei-la: 'a saúde é um estado de completo bem-estar físico, moral e social, não consistindo somente na ausência de enfermidade ou de doença"”. (Canguilhem, 2005, p.42-3, grifos do autor).

4. Beba com moderação é a frase que se lê/ouve em todos os comerciais impressos e audiovisuais das campanhas de venda de bebidas alcoólicas em nosso país, o que, diante dos tantos apelos ao consumo - seja pela profusão de marcas quanto pela frequência de exposição às peças comerciais, torna-se, ironicamente, uma advertência inócua.
Essa tese nos parece particularmente relevante por remeter a um pensamento recorrente nos discursos sobre saúde na atualidade: o de que as experiências vividas devam ser avaliadas de modo negativo ou positivo de acordo com sua intensidade, sendo atitudes de moderação ${ }^{4}$ a chave do bem-viver. Esse raciocínio, por sua vez, leva-nos a um óbvio desdobramento: desejável, portanto, será tudo aquilo que fuja aos extremos, que corresponda à média, à norma, o que nos leva à outra conclusão: para sermos saudáveis, precisamos ser normais. Mas quais implicações estão contidas nessa assertiva? 


\section{0 poder, a norma e a vida com qualidade}

Acompanhadas por Castro (2009, p.309), retomemos a discussão sobre o poder e a sua relação com a norma em nossa sociedade:

o poder, para Foucault, na sua forma moderna, se exerce cada vez mais em um domínio que não é o da lei, e sim o da norma e, por outro lado, não simplesmente reprime uma individualidade ou uma natureza já dada, mas, positivamente, a constitui, a forma.

Assim, para Foucault (2001, p.62):

a norma não se define como uma lei natural, mas pelo papel de exigência e coerção que é capaz de exercer em relação aos domínios nos quais se aplica. A norma é portadora, consequentemente, de uma pretensão de poder. A norma não é, sequer ou simplesmente, um princípio de inteligibilidade; ela é um elemento a partir do qual determinado exercício de poder encontra-se fundado e legitimado. Conceito polêmico, dizia Canguilhem. Talvez se pudesse dizer: político.

A essa altura, pensamos não ser difícil perceber o entrelaçamento entre tais questões e o campo da educação em saúde, uma vez que práticas educativas, sobretudo as concernentes à saúde, fundam-se em normas, regras balizadoras de comportamentos considerados saudáveis ${ }^{5}$, práticas intrinsecamente políticas.

Vale, agora, um esclarecimento: não se trata de demonizar as práticas educativas em saúde, reduzindo-as a um amontoado de prescrições a serviço do "capetalismo"; não pretendemos denunciar uma suposta luta do mal contra o bem. Aprendemos com Foucault que não há posições definitivamente alcançadas, mas um perpétuo jogo de forças entre o que pode ser considerado mal e bem,

5. Não por acaso, a Rede Globo de Televisão lançou recentemente programa intitulado Bem Estar, cujas chamadas no portal de notícias da emissora são bastante reveladoras do investimento biopolítico que busca modelar o processo de envelhecimento de nossa população diante das projeções demográficas que apontam para o expressivo aumento do número de idosos não apenas em nosso país, mas no mundo: "otimismo, autoeficácia e autoestima são chave da longevidade, diz médico"; "ter autoestima é uma forma de envelhecer bem"; "geriatra e preparador físico tiram dúvidas da internet sobre exercícios"; "especialistas tiram dúvidas sobre envelhecimento saudável”; “ficar parado envelhece". Disponível em: 〈http://busca. globo.com/Busca/g1/?query=programa+bem+estar\&ord enaca $0=$ descending $\&$ offset $=1 \&$ xargs $=\&$ format $0=\&$ requis itor $=g 1 \&$ aba $=$ todos\&filtro=agregadorproduto $\% 3 \mathrm{~A} \% 5 \mathrm{E} \% 2$ 2 Bem+Estar $\% 22 \% 24 \&$ on $=$ false\&formatos $=3413 \% 2 \mathrm{C} 3368$

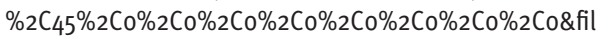
troData $=\&$ dataA $=\&$ dataB $=>$. Acesso em: 4 out. 2011 (ver link referente ao dia 7 mar. 2011).

6. Provocativa referência ao capitalismo, cunhada pelo "Profeta Gentileza", personagem que habita o imaginário carioca pelos numerosos pensamentos registrados nos pilares de diversos viadutos da cidade. Disponível em: 〈http://oimpressionista.wordpress.com/museu-virtual-gentileza/>. Acesso em: 4 out. 2011. 
noções indiscutivelmente relativas e condicionadas pelos regimes de verdade que ordenam a realidade de um certo modo, e não outro, em função das configurações sócio-históricas em questão.

Nossa proposta, portanto, consiste em discutir modos de fazer educação em saúde a partir da análise das práticas veiculadas pelo documentário eleito como fonte para o debate, práticas que trazem à tona a tensão que forja as lutas por poder em nossa sociedade.

Solitário Anônimo, como já foi dito, é um vídeo que, sem ter intenção explicitamente pedagógica, tem muito a ensinar. E ensina porque não prescreve, provoca. Faz refletir sobre as engrenagens que movem o fazer profissional no campo da saúde coletiva, pois, a despeito de o protagonista ser idoso, as questões por ele levantadas existenciais - não são exclusivamente suas ou intrínsecas à faixa etária a que pertence. Lembremos a pontuação de Foucault (2006a), em trecho já citado anteriormente, de que o suicídio se tornou alvo de análise sociológica por representar uma espécie de rachadura no sistema de regulação das populações: a despeito de todo o controle biopolítico, há os que tentam (e muitos efetivamente conseguem) dele escapar, ainda que de forma dramática e radical.

Pensar no suicídio como um fato social, aliás, desconfortavelmente frequente em nossos tempos, nos leva a refletir sobre o grau de satisfação dos indivíduos com o modo de vida que regula as sociedades a que pertencem. Assim, retomando o fio original deste trabalho, retomamos também a questão que dá sentido ao documentário: "[...] o paciente tentava se matar... Ou seria mais exato dizer que sua atitude consistia na recusa a viver de um certo modo?"

Trabalhar com a noção foucaultiana de cuidado de si para a invenção de novos modos de existência remete-nos, dentro do campo da educação em saúde, a questões intimamente relacionadas às noções de risco e qualidade de vida, ambas tão caras ao discurso hegemônico sobre prevenção e cuidado em saúde.

Chachamovich, Trentini e Fleck (2007, p.62) lembram-nos que, a despeito de 0 termo "qualidade de vida" ter sido referido pela primeira vez em 1966 , no editorial do periódico AnnalsofInternal Medicine, intitulado Medicine and Quality of Life, de autoria de Elkinton,

as pesquisas sobre temas relacionados a construtos de percepção subjetiva

7. Este periódico foi referido pelos autores citados, a saber, Chachamovich, Trentini e Fleck, na publicação de 2007. de satisfação iniciaram-se na literatura internacional em 1953, com a publicação de uma série de estudos 
conduzidos por Jones, um psicólogo americano da Universidade de Harvard, reunidos no livro The pursuitofhappiness. ${ }^{\mathbf{8}}$

Ainda segundo Chachamovich, Trentini e Fleck (2007, p.62), Elkinton criticava a prática médica da época, por conferir demasiada importância aos desenvolvimentos tecnológicos e técnicos às expensas da reflexão sobre o bem-estar e o grau de satisfação que tais conquistas poderiam proporcionar aos pacientes.

Quarenta e cinco anos se passaram, e parecemos andar em círculos, considerando, no caso brasileiro, a necessidade de criação, pelo Ministério da Saúde, de um programa de humanização ${ }^{9}$ em 2001, tornado política em $2003^{10}$. Aos menos favorecidos, nem mesmo o acesso aos avanços tecnológicos referidos por Elkinton é proporcionado em tempo hábil e de modo equânime, o que torna necessária e urgente toda reflexão que debata vigorosamente a formação dos profissionais de saúde, muitas vezes a única tecnologia efetivamente à disposição das camadas populares no sistema brasileiro de saúde. E, por formação, entenda-se não apenas rigor na competência técnica, mas também - e muito especialmente o resgate de uma competência no âmbito das relações interpessoais que há muito vem se tornando exceção nos serviços de saúde prestados à população ${ }^{11}$. Contudo, a questão que se impõe nesse momento é: como fazer isso? E não se trata de criar/ensinar/aprender mais uma técnica visando a mudanças comportamentais. A literatura acadêmica conta com uma profusão de trabalhos de educação em saúde que, valorizando o viés prescritivo das práticas educativas ${ }^{12}$, estimulam mudanças, mas não necessariamente transformações no modo de relação dos indivíduos consigo mesmos e com o mundo.

Entendemos com Vasconcelos (2006, p.274) que "para cuidar da pessoa inteira, é preciso estar presente como pessoa inteira” e, para tal, há que fomentar tal debate nas "instituições formadoras de recursos humanos" para a saúde, sendo a fi-

8. Observe-se o recrudescimento da 'felicidade' como objeto de análise em nossos tempos, destacando-se 0 instigante livro organizado por João Freire Filho, Ser feliz hoje: reflexões sobre o imperativo da felicidade. Rio de Janeiro: FGV, 2010.296 p.

9. Programa Nacional de Humanização da Assistência Hospitalar - PNHAH. Disponível em: 〈http://bvsms.saude.gov.br/bvs/publicacoes/pnhaho1.pdf〉. Acesso em: 4 out. 2011.

10. Política Nacional de Humanização da Atenção e Gestão do SUS - “HumanizaSUS”. Disponível em: 〈http:// portal.saude.gov.br/portal/saude/cidadao/area.cfm?id_ area $=1342>$. Acesso em: 4 out. 2011.

11. Não raros são os relatos de agradecimentos excessivamente efusivos por parte de pacientes e familiares a profissionais de saúde que, na cena de cuidado, nada mais fizeram do que cumprir com suas atribuições na forma do que se entende por atenção 'humanizada', preconizada em nossa legislação em saúde.

12. A esse respeito, ver: Paulino, L.F.; Fernandes, W. R.; Oliveira, A. C. C.; Siqueira, V. H. F.. A temática velhice no campo da educação: algumas reflexões a partir da análise de discursos em periódicos. In: Enpec - Encontro Nacional de Pesquisa em Educação em Ciências, 8., 2009, Florianópolis. Anais eletrônicos... Florianópolis: UFSC, 2009. Disponível em: 〈http://www.foco.fae.ufmg.br/viienpec/ index.php/enpec/viienpec/paper/viewFile/1719/493〉. Acesso em: 4 out. 2011. 
losofia e, cremos, muito especialmente as ideias foucaultianas, fonte de inspiração para a construção de práticas que respeitem o humano na multiplicidade de suas diferenças e necessidades. No entanto, como pontuam Castiel e Diaz, não se trata de subestimar o valor das ciências da saúde:

é preciso deixar claro que não se pretende adotar aqui uma postura anticientífica, obscurantista ou de menosprezo pelas abordagens empiricistas no terreno da saúde. Sem dúvida, alguns indiscutíveis avanços neste terreno são capazes de proporcionar melhores condições de saúde às pessoas que têm acesso a estas benesses. Mas há certos dilemas, perplexidades e talvez equívocos que poderiam ser mais bem abordados diante da assunção de que talvez estes discursos sanitários sejam compatíveis com o espírito de nossa época. E que até mesmo seriam sintomas destes tempos, mudando, assim, a ênfase hegemônica da discussão em termos tecnicistas para incluir as negligenciadas dimensões filosóficas da produção do conhecimento.(Castiel; Diaz, 2007, p.32).

Não se trata, portanto, de rechaçar a relevância dos avanços tecnológicos, mas de refletir sobre a maneira como nós, sociedade em geral, e, mais especificamente, quando investidos no papel de profissionais de saúde, temo-nos apropriado de todo esse aparato. E pensar o uso da tecnologia a serviço da saúde forçosamente nos remete à discussão sobre a ideia de risco, uma vez que o fazer científico nessa área é movido pela necessidade de mantê-lo sob controle.

Concordando com Castiel e Diaz (2010, p.118), entendemos que:

discursos sobre saúde (e, mais especificamente, sobre riscos à saúde) consistem em construções contingentes, de caráter normativo, inapelavelmente vinculadas a outros interesses. Dependem, explicitamente ou não, de definições do que é ser humano, do tipo de sociedade que se almeja e dos modos de atingi-la.

Importante enfatizar o caráter contingente da noção de risco, uma vez que o valor conferido na atualidade às "evidências" no campo das pesquisas e práticas em saúde conduz, inevitavelmente, ao raciocínio de que, se quisermos viver bem - e por muito 
tempo -, devemos acatar o que é preconizado pela ciência, sobretudo se "régia" for, como é o caso da medicina (Foucault apud Castro, 2009, p.210). Embora se possa questionar a pureza do estatuto de cientificidade atribuído à medicina, discutindo o quanto haveria de arte em sua constituição ${ }^{13}$, tal debate, ainda que interessante, escaparia ao escopo deste breve ensaio.

De todo modo, tal sinalização nos serve de base para realçar a necessária verve criativa que torna o exercício profissional, não apenas no âmbito da medicina, mas no de outras profissões da área da saúde, uma aventura cotidiana: há que sermos um tanto artistas para lidar com a imprevisibilidade do humano, pois, como nos lembram Castiel e Diaz (2010, p.8), “[...] viver implica correr riscos”. No entanto, mais do que um apelo reflexivo aos profissionais de saúde e aos docentes da área, é importante que todos (as) assumamos os inevitáveis riscos implicados no viver, desde que tal atitude faça emergir "pelas artes da existência”, um "eu ético" (Gros, 2006, p.127). Ainda com Gros (2006), entendemos que "isto significa que o sujeito é compreendido como transformável, modificável: é um sujeito que se constrói, que se dá regras de existência e conduta, que se forma através dos exercícios, das práticas, das técnicas, etc."

Candiotto (2008, p.93, grifo nosso), em outras palavras, corrobora o dito e acrescenta: “a razão de ser do cuidado [de si] [...] se refere à arte de viver (tékhnetoûbíou) a ser desenvolvida ao longo da existência, desdobrando-se nas funções de luta, de crítica e de terapia. Função de luta, posto que "é preciso dispor de armas adequadas (paraskeuê)" para enfrentar as dificuldades existenciais; função de crítica, uma vez que é necessário exercitar a correção das condutas, desprendendo-se de maus hábitos; função terapêutica, na medida em que a tarefa essencial do cuidado de si consiste em tornar o sujeito “médico de si próprio" pela atenção permanente ao corpo e à alma, cabendo a última à filosofia.

É, pois, quando o indivíduo toma para si a responsabilidade por sua própria existência e, aqui, ressaltamos, tal noção nada tem a ver com a "visão moralista [...] [que] procura localizar e punir responsáveis/culpados [...]” (Castiel, Diaz, 2010, p.120) por eventuais faltas cometidas, e incorpora a ideia de que todos (as) carregamos o germe da transformação - nossa e do mundo - , é nesse momento que se dá a verdadeira aliança terapêutica irredutível à clínica, posto que atravessa o campo de todas as ações humanas, em especial daquelas que se pretendem realmente pedagógicas.

13. A esse respeito, ver Luz, M. T.: Biomedicina e racionalidade científica no ensino contemporâneo da área de saúde. In: Souza, A. N.; Pitanguy, J. (Org.) Saúde, corpo e sociedade. Rio de Janeiro: Editora UFRJ, 2006. p.195. 
Em tempos de massificação e anestesia, façamos um recuo histórico (Candiotto, 2008, p.94, grifo nosso) para refletir sobre nossas atitudes perante a vida:

[...] na cultura greco-romana, o cuidado de si é universalizado como princípio e posto em prática de modo particularizado. [...] todos são virtualmente capazes de exercê-lo, poucos são aqueles que efetivamente alcançam transformá-lo em atitude permanente. 0 critério de diferenciação está situado entre aqueles que escolhem o cuidado de si como modo de vida, e os demais, que não dedicam a ele tempo suficiente.

De volta ao vídeo, perguntamos: e se a noção de "cuidado de si" fosse a baliza da atuação daqueles profissionais? E se, por mais improvável que fosse, o paciente tivesse sido tomado como "médico de si próprio", tendo sua atitude compreendida como uma resposta possível ao seu modo de viver a vida até aquele momento?

Como pudemos observar nos planos finais, o paciente, ouvido em seus argumentos pela "emoção, intuição e sensibilidade" (Vasconcelos, 2006, p.275) da cineasta, que, aliás, frise-se, desempenha nas filmagens função nitidamente terapêutica, em nada se assemelha àquele visto pela equipe assistencial em todos os planos anteriores.

Diante disso, podemos imaginar que, se as disciplinas e regulações biopolíticas tivessem sido postas em suspenso por algum tempo, de modo a que se ouvisse a voz de um solitário que talvez não se pretendesse tão anônimo assim, o cuidado poderia ter sido realmente experimentado como tal por todos - paciente e agentes de cuidados.

Que tais questionamentos nos sirvam de inspiração em nossas práticas cotidianas, docentes e assistenciais, de modo a esculpirmos mais um precioso detalhe das “obras de arte" que devam ser nossas existências (Portocarrero, 2009, p.227) em meio ao "campo de tensão aberto entre os limites que nos determinam e sua ultrapassagem possível, tensão inesgotável na qual a razão tem de decidir se fica ou não a serviço da liberdade, campo de expressão maior do humano.” (Branco, 2007, p.13). 


\section{Referências bibliográficas}

BRANCO, G. C. Foucault em três tempos. Mente, cérebro e filosofia. A dissolução do sujeito. São Paulo: Duetto, p. 6-13, ago. 2007.v. 6. Foucault e Deleuze.

CANDIOTTO, C. Subjetividade e verdade no último Foucault. Trans/Form/Ação, São Paulo, v. 31, n. 1, p. 87-103, 2008.

CANGUILHEM, G. Escritos sobre medicina. Rio de Janeiro: Forense Universitária, 2005.p. 35-48.

CANGUILHEM, G. O normal e o patológico. 6. ed. rev. Rio de Janeiro: Forense Universitária, 2009.

CANGUILHEM, G. A saúde: conceito vulgar e questão filosófica. In: CASTIEL, L.D.; DIAZ, C.A.D. Discursos sobre riscos e comportamentos sadios baseados em evidências. In: CASTIEL, L.D.; DIAZ, C.A.D. A saúde persecutória: os limites da responsabilidade. Rio de Janeiro: Editora FIOCRUZ, 2007.p. 55-66.

CASTRO, E. Vocabulário de Foucault - um percurso pelos seus temas, conceitos e autores. Belo Horizonte: Autêntica, 2009.

CHACHAMOVICH, E.; TRENTINI, C.; FLECK, M. P. A. Qualidade de vida em idosos: conceituação e investigação. In: NERI, A. L. (Org.). Qualidade de vida na velhice: enfoque multidisciplinar. Campinas: Alínea, 2007.

DREYFUS, H. L.; RABINOW, P. Michel Foucault, uma trajetória filosófica: para além do estruturalismo e da hermenêutica. Rio de Janeiro: Forense Universitária, 1995.

DUARTE, R. M. Pedagogias da imagem cinematográfica. In: SEMINÁRIO BRASILEIRO DE ESTUDOS CULTURAIS E EDUCAÇÃO - PEDAGOGIAS SEM FRONTEIRAS, 3. 2008. Canoas/RS. 2008.Disponível em: 〈http://www.moodle.ufba.br/file.php/10010/linguagens/pedagogias_imagem_cinematogr_ficapdf〉. Acesso em: 15 abr. 2011.

FOUCAULT, M. Os anormais. Curso no Collège de France (1974-1978). São Paulo: Martins Fontes, 2001.

FOUCAULT, M. Direito de morte e poder sobre a vida. In: FOUCAULT, M. História da Sexualidade 1 - a vontade de saber. 17. ed. Rio de Janeiro: Graal, 2006a. p. 145 et seq.

FOUCAULT, M. A vida dos homens infames. In: MOTTA, M.B. (Org.). Estratégia, poder/ saber. 2. ed. Rio de Janeiro: Forense Universitária, 2006b. p. 203-222. Col. Ditos e Escritos. v. 4.

GROISMAN, D. A velhice, entre o normal e o patológico. História, Ciências, Saúde, Manguinhos, Rio de Janeiro, v. 9, n. 1, p. 61-78, jan./abr. 2002.

GROS, F. O cuidado de si em Michel Foucault. In: RAGO, M.; VEIGA-NETO, A. (Org.) Figuras de Foucault. Belo Horizonte: Autêntica, 2006. p. 127-138. 
MACHADO, R. (Org.). Por uma genealogia do poder. In: FOUCAULT, M. Microfísica do poder. 25. ed. São Paulo: Graal, 2008. Introdução, p. vii- xxiii.

PORTOCARRERO, V. Vida, genealogia da ética e estética da existência. In: PORTOCARRERO, V. As ciências da vida: de Canguilhem a Foucault. Rio de Janeiro: Editora FIOCRUZ, 2009.

SÁ, M. B.; SIQUEIRA, V. H. F. Um exercício para investigação em acervo de vídeos educativos em saúde: utilizando as noções de acontecimento e arquivo. In: REUNIÃO ANUAL DA ANPED - SOCIEDADE, CULTURA E EDUCAÇÃO: NOVAS REGULAÇÕES?, 32., 2009.Caxambu/MG. Disponível em: 〈http://www.anped.org.br/reunioes/32ra/trabalho_gt_16.html. Acesso em: 15 abr. 2009.

VASCONCELOS, E. M. Formar profissionais de saúde capazes de cuidar do florescer da vida. In: VASCONCELOS, E. M.; FROTA, L. H.; SIMON, E. (Org.). Perplexidade na Universidade: vivências nos cursos de saúde. São Paulo: Hucitec, Edições Mandacaru, 2006. Reflexões, item 2, p. 265 et seq.

Submetido à publicação em 16 de novembro de 2011. Versão final aprovada em 30 de julho de 2012. 